\title{
High mobility group B1 protein interacts with its receptor RAGE in tumor cells but not in normal tissues
}

\author{
JORDANA TODOROVA and EVDOKIA PASHEVA \\ Institute of Molecular Biology, Bulgarian Academy of Sciences, Sofia, Bulgaria \\ Received May 31, 2011; Accepted October 4, 2011
}

DOI: $10.3892 / \mathrm{ol} .2011 .459$

\begin{abstract}
The high mobility group box 1 (HMGB1) protein is an abundant non-histone component of chromatin well known for its two DNA binding domains, HMG box A and HMG box $\mathrm{B}$. The main characteristics of the HMGB1 protein as an 'architectural' factor are its ability to recognize and bind with high affinity to distorted DNA and its ability to induce kinks in linear DNA fragments. The HMGB1 protein has been correlated to cancer progression. An elevated expression of HMGB1 occurred in certain types of primary tumor, including melanoma and colon, prostate, pancreatic and breast cancers, and in the majority of cases HMGB1 is associated with invasion and metastasis. The main signaling pathway is activated through the interaction of HMGB1 with its Receptor for Advanced Glycation End products (RAGE). Certain data indicate that an elevated expression of RAGE and HMGB1 is not always a prerequisite of poor prognosis of tumor development. The cellular localization of the ligand/receptor pair also requires consideration. The data concerning the expression of HMGB1 protein and its receptor RAGE in various tissues and tumor cells reflect the overall production of the proteins. However, they do not refer to their cellular localization and there is no direct evidence for the formation of a stable complex between them. In the present study, we investigated the subcellular distribution of HMGB1 and its receptor RAGE in various rat organs compared to Guerin ascites tumor cells. In the normal tissues the proteins exist in their soluble form, whereas in the tumor cells they are insoluble and membranebound. HMGB1 forms a stable complex with RAGE only in the protein extract derived from the cancer cells predominantly in the membrane fraction.
\end{abstract}

Correspondence to: Professor Evdokia Pasheva, Institute of Molecular Biology, Bulgarian Academy of Sciences, 21 Acad. G. Bonchev Str., Sofia 1113, Bulgaria

E-mail: eva@bio21.bas.bg

Key words: HMGB1 protein, RAGE, tumorigenesis, subcellular localization

\section{Introduction}

The high mobility group box 1 (HMGB1) protein is an abundant non-histone component of chromatin. It is well known for its two DNA binding domains, HMG box A and HMG box B. The HMG box motive was also detected in a number of regulatory factors including UBF, Lef-1, SRY and SSRP (1). The main characteristics of HMGB1 protein are i) its capability to recognize and bind with high affinity to distorted DNA, such as cruciform DNA, UV and cisplatin-damaged DNA (2-4) and ii) its ability to induce kinks in linear DNA fragments $(5,6)$. These characteristics identify the protein as an 'architectural' factor, facilitating the assembly of certain nucleoprotein complexes, and render it a key participant in fundamental nuclear events including repair (7), replication (8) and remodeling (9-10). In previous years, the extracellular functions of HMGB1 protein have gained scientific interest. It was revealed that monocytes/ macrophages actively secreted HMGB1 in response to various stimuli (11) and that, once secreted, HMGB1 was capable of activating other cells involved in immune response or inflammatory reactions, thus acting as a cytokine itself $(12,13)$. The protein can also be passively released by damaged or necrotic cells, leading to inflammation (14). A number of post-translational modifications including acetylation (15), phosphorylation (16), methylation (17) and poly(ADP)-ribosylation (18) have been suggested to direct HMGB1 to the secretory pathway.

The HMGB1 protein has been associated with cancer progression. An elevated expression of HMGB1 was observed in certain primary tumors including melanoma and colon, prostate, pancreatic, and breast cancers (19). In the majority of cases, HMGB1 was associated with invasion and metastasis. The protein was proposed to be directly involved in tumor cell metastasis through its ability to promote cell migration, modulate the adhesive properties of cells and modify components of the extracellular matrix $(20,21)$. The experiments carried out using C6 glioma cells, an example of highly invasive cells, demonstrated that inhibition of HMGB1 expression by anti-sense oligonucleotides or inhibition of the protein function by anti-HMGB1 antibodies markedly inhibited cell migration (21). Mounting evidence show that the main signaling pathway is activated through the interaction of HMGB1 and its Receptor for Advanced Glycation End products (RAGE). The significance of this pathway in vivo was indicated by the observation that blockade of the HMGB1/RAGE interaction suppressed tumor growth and metastasis in lung cancer (22). One 
probable mechanism is that the HMGB1/RAGE complex induces depletion of macrophages in colon cancer (23). The lack of host defense, therefore, becomes conducive to tumor spread.

RAGE is constitutively expressed during embryonic development and its expression is downregulated in adult life. However, known exceptions are the skin and lung, which constitutively express RAGE throughout life. The majority of other cells, including monocytes/macrophages, endothelial and smooth muscle cells, fibroblasts and neuronal cells, do not produce significant amounts of RAGE under physiological conditions but may be induced to express RAGE in situations where ligands accumulate (24). Several findings have indicated that the elevated expression of RAGE was not always a prerequisite of poor prognosis of tumor development. The cellular localization of the receptor should also be taken into consideration. In colorectal adenomas, the cytosolic pattern was associated with mild atypia and small tumor size, whereas the membranous pattern was correlated to severe atypia, villous histological type and elevated levels of HMGB1 protein. These results indicated that RAGE expression, particularly with a membranous pattern, was associated with the malignant potential of colorectal adenomas (25). Immunohistochemistry revealed that RAGE exhibited dot-like cytoplasmic localization in primary hepatocellular and colorectal carcinomas, which changed to dense brown staining across the metastatic cells due to membranous expression (26).

The data concerning the expression of HMGB1 protein and its receptor RAGE in various tissues and tumor cells mainly reflect the overall production of the proteins. However, these data do not refer to the cellular localization of HMGB1 and RAGE and there is no direct evidence for the formation of a stable complex between the two proteins. We examined the expression of HMGB1 protein and its receptor RAGE in different rat organs and in Guerin ascites tumor cells in respect to their localization and complex formation.

\section{Materials and methods}

Preparation of total protein extract. Guerin ascites tumor cells were inoculated in albino rats. The ascite liquid was collected 7 days after transplantation together with $2 \mathrm{~g}$ of tissue samples. The total protein extracts were prepared as described by Dignam (27). The material was manually homogenized on ice in lysis buffer [5 mM Tris- $\mathrm{HCl}, \mathrm{pH}$ 7.4, $2 \mathrm{mM}$ EDTA, $1 \%$ Triton 100, 1 mM PMSF and protease inhibitor mix (Boehringer, Mannheim, Germany)], sonicated, centrifuged at $500 \mathrm{x}$ g for $30 \mathrm{~min}$ and aliquoted at $-80^{\circ} \mathrm{C}$.

Preparation of soluble and membrane protein extracts. The tissue samples were washed in cold phosphate-buffered saline (PBS), fast-frozen in liquid nitrogen, homogenized in $5 \mathrm{mM}$ Tris-HCl, pH 7.4, 2 mM EDTA, 1\% Triton 100, 1 mM PMSF and protease inhibitor mix (Boehringer) and centrifuged at $500 \mathrm{x}$ g for $30 \mathrm{~min}$ at $4^{\circ} \mathrm{C}$. The samples were then washed twice with the same buffer and the collected supernatants were centrifuged at $45,000 \mathrm{x}$ g for $30 \mathrm{~min}$ at $4^{\circ} \mathrm{C}$. The supernatant was considered as the 'soluble fraction'. The pellet was suspended in $75 \mathrm{mM}$ Tris, pH 7.4, $12.5 \mathrm{mM} \mathrm{MgCl}, 5 \mathrm{mM}$ EDTA and considered as the 'membrane fraction'. The samples were aliquoted and stored at $-80^{\circ} \mathrm{C}$.
Immunoblotting. Samples (80-100 $\mu \mathrm{g}$ of protein extract) were resolved on SDS-18\% polyacrylamide gel and transferred to nitrocellulose membranes (Schleicher \& Schuell, Dassell, Germany) at $4^{\circ} \mathrm{C}$ for $1 \mathrm{~h}$ at $8 \mathrm{~V} / \mathrm{cm}$ in a buffer containing $25 \mathrm{mM}$ Tris, $\mathrm{pH} 8.2,192 \mathrm{mM}$ glycine and $15 \%$ methanol. The membranes were blocked for $1 \mathrm{~h}$ in $10 \%(\mathrm{w} / \mathrm{v})$ non-fat dry milk in TBST buffer (10 mM Tris, pH 7.5, $150 \mathrm{mM} \mathrm{NaCl}$, $0.1 \%$ Tween-20) and incubated for $2 \mathrm{~h}$ at room temperature with various primary antibodies diluted at 1:1000. The antibodies included: polyclonal rabbit anti-HMGB1 antibody (Upstate), monoclonal mouse anti-RAGE antibody (Santa Cruz Biotechnology, Santa Cruz, CA, USA) and mouse monoclonal anti-actin antibody AC-15 as a reference (Sigma Immunochemicals, St. Louis, MO, USA). The secondary antibodies 680 conjugated goat (polyclonal) anti-mouse IgG (LI-COR, Lincoln, NE, USA) and $800 \mathrm{CW}$ conjugated goat (polyclonal) anti-rabbit IgG (LI-COR) were used at a dilution of 1:3000 to visualize immunoreactivity. Immunoreactivity was detected using the chemiluminescent method (Odyssey Infrared Imaging System, Amersham, Buckinghamshire, UK).

Immunoprecipitation. Immunoprecipitation with the monoclonal anti-RAGE antibody (Santa Cruz Biotechnology) was carried out according to the manufacturer's instructions. The antibody $(2 \mu \mathrm{g})$ was incubated with $100 \mu \mathrm{l}(5 \mu \mathrm{g} / \mu \mathrm{l})$ protein extract at $4^{\circ} \mathrm{C}$ with gentle agitation. After $1 \mathrm{~h}$, Protein A-Sepharose (Zymed Laboratories, San Francisco, CA, USA) was added for an additional incubation period of $1 \mathrm{~h}$. The sepharose beads were washed twice with RIPA buffer $(50 \mathrm{mM}$ Tris-HCl, pH 7.4, 1\% NP-40, 0.25\% Na-deoxycholate, $150 \mathrm{mM}$ $\mathrm{NaCl}, 1 \mathrm{mM}$ EDTA and protease inhibitors) and PBS, and boiled in $0.5 \%$ SDS for $10 \mathrm{~min}$. The proteins were analyzed using sodium dodecyl sulfate polyacrylamide gel electrophoresis and Western blotting.

\section{Results}

Expression level of $H M G B 1$ protein and its receptor $R A G E$ in rat normal tissues and tumor cells and their distribution in soluble and membrane fractions. Using immunoblotting, we examined the total expression level of HMGB1 protein and its receptor RAGE in various rat organs including the liver, lung, testis and spleen, as well as Guerin ascites tumor cells. The two proteins were detected in the tested specimens as their amount varied in the different organs and tumor cells (Fig. 1). The HMGB1 production was higher in the lung, liver and spleen and lower in the kidney as previously reported for older animals (28). In the normal tissues RAGE levels were elevated in the lung, which constitutively expressed the receptor throughout life. It should be noted that the highest protein amounts were registered in the Guerin tumor cells. In the majority of cases the increased production of HMGB1 and RAGE was correlated to tumor development and poor prognosis (19); however, a number of exceptions were reported. Although HMGB1 was overexpressed in the majority of tumors, tumors devoid of HMGB proteins have also been found. For example, adrenal gland carcinoma exhibited no HMGB1 expression (29). A marked intertumoral variation of HMGB1 expression was observed in various breast cancers (30). This was also the case for 
A

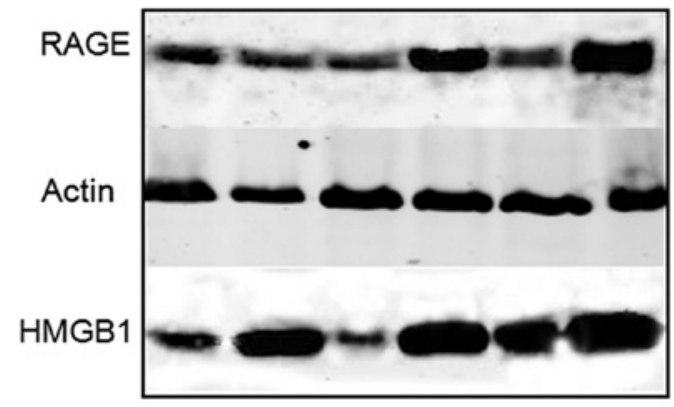

B

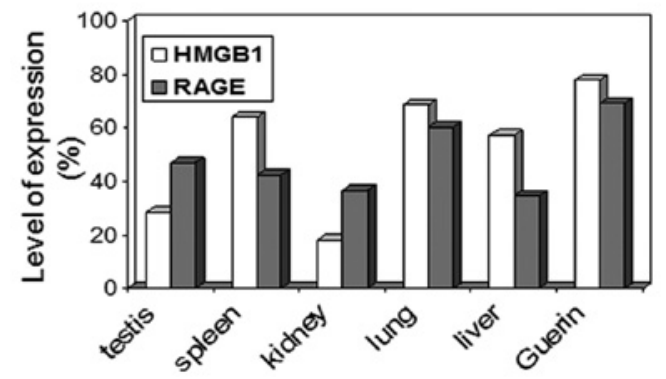

Figure 1. Expression levels of HMGB1 protein and its receptor RAGE in various rat tissues and Guerin ascite tumor cells. (A). Immunoblot analysis of total protein extracts. Samples (80-100 $\mu \mathrm{g}$ of protein extract) were resolved on SDS-18\% polyacrylamide gel, transferred to nitrocellulose membranes and incubated with various primary antibodies at a dilution of 1:1000. Positive immunoreactivity was visualized using secondary antibodies at a dilution of 1:3000 and detected by the chemiluminescent method. (B). The data from the gel-based quantification assay carried out using a Gel-pro analyzer are shown. The results are from three different experiments.

RAGE: in non-small cell lung carcinomas RAGE expression was strongly reduced (31).

Given that the overall expression of HMGB1 and RAGE is not always considered to be an indicator for cancer progression, we examined the distribution of the two proteins in soluble and membrane fractions of normal tissues and tumor cells. The results are shown in Fig. 2. In the rat organ specimens, HMGB1 protein was mainly observed in the soluble fraction and lesser amounts were recovered from the insoluble membrane fractions (Fig. 2B). These findings are in agreement with previously reported data that the bulk of the protein remained in the supernatant following high speed centrifugation; however, part of the protein sedimented with the microsomal membrane fraction (32). Similar results were obtained for RAGE distribution in normal tissues (Fig. 2A). Although the receptor was considered a membrane protein it was expressed as the full-length, membrane-bound form and various soluble forms lacking the transmembrane domain. Soluble RAGE was produced by the proteolytic cleavage of full-length RAGE and alternative mRNA splicing. The soluble isoforms included the extracellular domains but lacked the transmembrane and cytoplasmic domains (33). Again, the tumor cells exhibited a markedly different localization pattern for HMGB 1 protein and its receptor RAGE in comparison with the normal tissues. The two proteins were predominantly observed in the insoluble membrane fraction (Fig. 2A and B, compare soluble/membrane Guerin with soluble/membrane normal tissue). Notably, the overall expression of RAGE was almost comparable in lung and tumor cells (Fig. 1B). However,
A

RAGE

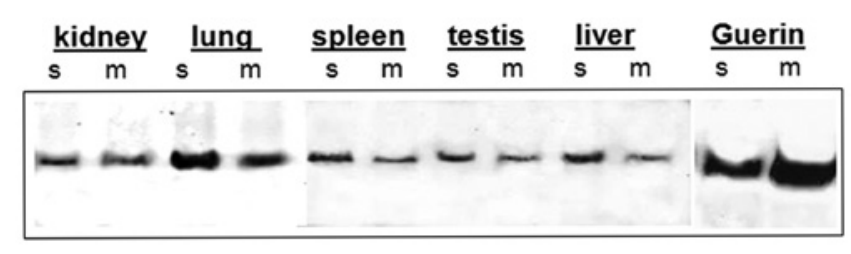

B HMGB1

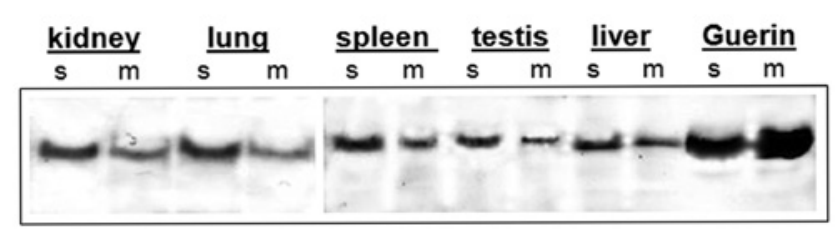

Figure 2. Subcellular distribution of the HMGB1 protein and its receptor RAGE in different rat tissues and Guerin ascites tumor cells. (A) The subcellular distribution of RAGE and (B) the HMGB1 protein in soluble (s) and membrane $(\mathrm{m})$ fractions was analyzed using immunoblotting under the conditions described in Materials and methods.

whereas in lung tissue the receptor was mainly observed in its soluble form, RAGE was predominantly membrane-bound in the Guerin tumor cells. The distribution pattern also differed for HMGB1 protein: HMGB1 was chiefly soluble in the protein extract from normal tissues, whereas it mainly occurred in its insoluble membrane form in cancer cells (Fig. 2B). Our results confirm the hypothesis that the cellular localization of HMGB1 protein and its receptor RAGE should be considered as a more reliable indicator of tumor progression instead of the total protein expression level.

$H M G B 1$ protein interacts with its receptor RAGE only in tumor cells. The question remains as to whether the overexpression of HMGB1 and its receptor RAGE always leads to the formation of a ligand/receptor complex. To examine this possibility, we performed immunoprecipitation with antiRAGE antibody of the soluble and membrane fractions and revealed immunoreactivity by incubation with anti-HMB1 antibody. We selected the protein extracts from the lung as a control, since the RAGE level was higher in this normal tissue. We applied the same approach to Guerin tumor cells. Immunoprecipitation with anti-RAGE antibody and the subsequent findings of the immunoblot analysis with anti-HMB1 antibody provided no signal in the soluble or membrane fraction derived from rat lung samples (Fig. 3A, lanes 2 and 3). To verify that the immunoprecipitation was effective, we performed the same experiment with the exception that the transfer membrane was incubated with anti-RAGE antibody. The positive signals (Fig. 3, lanes 1 and 2) in the soluble and membrane fractions demonstrated that receptor molecules were bound to the antibody, but the receptor clearly did not carry the HMGB1 protein. By contrast, in the case of the tumor cells visualization with the anti-HMGB1 antibody of the anti-RAGE precipitated complex provided a clearly positive signal in the membrane fraction, indicating that the HMGB1 protein formed a stable complex with its receptor RAGE (Fig. 3, lane 2). In the soluble extract, HMGB1 was also associated with the receptor but the 
A

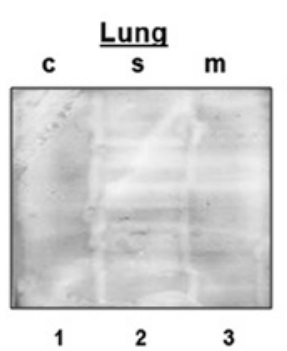

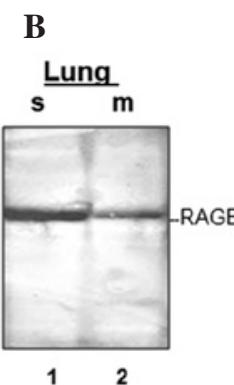

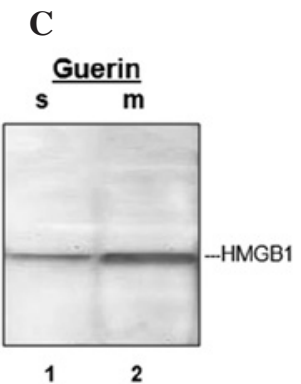

Figure 3. Complex formation between the HMGB1 protein and its receptor RAGE in normal tissue and Guerin ascite tumor cells. The interaction between HMGB1 protein and its receptor RAGE was analyzed by immunoprecipitation with monoclonal mouse anti-RAGE antibody. (A) The specifically immunoprecipitated proteins of soluble (lane 2) and membrane (lane 3) fractions from the lung were resolved on SDS-18\% polyacrylamide gel, transferred to nitrocellulose membranes and visualized using polyclonal rabbit anti-HMGB1 antibody. A control experiment (c) was carried out with protein-A beads incubated with total protein lung extract to exclude nonspecific binding (lane 1). (B) The specifically immunoprecipitated proteins of soluble (lane 1) and membrane (lane 2) fractions from the lung were resolved on SDS-18\% polyacrylamide gel, transferred to nitrocellulose membranes and visualized using monoclonal mouse anti-RAGE antibody. The positive signal is marked. (C). The specifically immunoprecipitated proteins of soluble (lane 1) and membrane (lane 2) fractions from Guerin ascite tumor cells were resolved on SDS-18\% polyacrylamide gel, transferred to nitrocellulose membranes and visualized using polyclonal rabbit anti-HMGB1 antibody. The positive signal is marked.

interaction was probably weaker as a less intensive signal was detected (Fig. 3, lane 1).

\section{Discussion}

The coexistence in the cell of the HMGB1 protein and its receptor RAGE in relatively higher levels is not a necessary prerequisite for complex formation and cancer development. The quantities of the proteins distributed in the membrane and soluble fractions should be investigated. As we demonstrated, in the normal tissue the receptor was predominantly observed in its soluble form, whereas in the Guerin ascites tumor cells it changed to the membrane-bound form. The soluble RAGE (sRAGE) acts as a decoy that prevents ligands from interacting with the cell surface receptor. The application of sRAGE in vitro and in vivo resulted in an effective blockade of RAGE, in accordance with this decoy mechanism, in a range of animal models (24). sRAGE prevented the development of micro- and macrovascular diseases in rodents and also protected the animals from tumor metastasis and growth of primary tumors (22). By contrast, membrane-bound RAGE was generally associated with metastatic potential and poor prognosis $(25,26)$. The bulk of HMGB1 protein was generally found in the soluble fraction following high speed centrifugation (32); however, in certain cases the protein may alter its subcellular localization. For example, upon platelet activation, part of HMGB1 was associated with the plasma membrane (34). In murine erythroleukemia (MEL) cells, following induction with hexamethylene bisacetamide, HMGB1 protein accumulated in a membrane-bound form (35). In our case, we observed increased quantities of HMGB1 protein in the tumor cells with prevailing membrane localization, which we consider to be a clear characteristic of cancer development. Furthermore, we determined a stable HMGB1/RAGE complex in the tumor cells alone, mainly occurring in the membrane fraction. The data presented in this study indicate that during tumorigenesis, HMGB1 protein and its receptor RAGE undergo cellular redistribution required for the stable protein/protein interaction. Other factors are also indispensible for the formation of a stable receptor/ligand complex, since in the normal tissues the two proteins coexist in the membrane fraction in smaller quantities. However, no association was identified.

\section{Acknowledgements}

This study was supported by grant DTK 02/80 from the National Science Fund.

\section{References}

1. Thomas JO and Travers A: HMG1 and 2, and related 'architectural' DNA-binding proteins. Trends Biochem Science 26: 167-174, 2001.

2. Bianchi ME, Bertrame M and Paonessa G: Specific recognition of cruciform DNA by nuclear protein HMG1. Science 243: 1056-1059, 1989.

3. Pil PM and Lippard SJ: Specific binding of chromosomal protein HMG1 to DNA damaged by the anticancer drug cisplatin. Science 256: 234-237, 1992.

4. Pasheva EA, Pashev IG and Favre A: Preferential binding of high mobility group 1 protein to UV-damaged DNA. Role of the COOH-terminal domain. J Biol Chem 273: 24730-24736, 1998.

5. Paull T, Hakynson MJ and Johnson RC: The nonspecific DNA-binding and bending proteins HMG1 and HMG2 promote the assembly of complex nucleoprotein structures. Genes Dev 7: 1521-1534, 1993.

6. Onate SA, Prendergast P, Wagner JP, Nissen M, Reeves R, Pettijhon DE and Edwards DP: The DNA-bending protein HMG-1 enhances progesterone receptor binding to its target DNA sequences. Mol Cell Biol 14: 3375-3391, 1994.

7. Ugrinova I,Zlateva S, Pashev IG and Pasheva EA: Native HMGB1 protein inhibits repair of cisplatin-damaged nucleosomes in vitro. Int J Biochem Cell Biol 41: 1556-1562, 2009.

8. Topalova D, Ugrinova I, Pashev IG and Pasheva EA: HMGB1 protein inhibits DNA replication in vitro: a role of the acetylation and the acidic tail. Int J Biochem Cell Biol 40: 1536-1542, 2008.

9. Bonaldi T, Langst G, Strohner R, Becker PB and Bianchi ME: The DNA chaperone HMGB1 facilitates ACF/CHRAC dependent nucleosome sliding. EMBO J 21: 6865-6873, 2002.

10. Ugrinova I, Pashev IG and Pasheva EA: Nucleosome binding properties and co-remodeling activities of native and in vivo acetylated HMGB-1 and HMGB-2 proteins. Biochemistry 48: 6502-6507, 2009.

11. Wang H, Bloom O, Zhang M, Vishnubhakat JM, Ombrellino M, Che J, Frazier A, Yang H, Ivanova S, Borovikova L, Manogue KR, Faist E, Abraham E, Andersson J, Andersson U, Molina PE, Abumrad NN, Sama A and Tracey KJ: HMG-1 as a late mediator of endotoxin lethality in mice. Science 285: 248-251, 1999.

12. Andersson U, Wang H, Palmblad K, Aveberger AC, Bloom O, Erlandsson-Harris H, Janson A, Kokkola R, Zhang M, Yang H and Tracey KJ: High mobility group 1 protein (HMG-1) stimulates proinflammatory cytokine synthesis in human monocytes. J Exp Med 192: 565-570, 2000.

13. Degryse B and De Virgilio M: The nuclear protein HMGB1, a new kind of chemokine. FEBS Lett 553: 11-17, 2003.

14. Scaffidi P, Misteli T and Bianchi ME: Release of chromatin protein HMGB1 by necrotic cells triggers inflammation. Nature 418: 191-195, 2002.

15. Bonaldi T, Talamo F, Scaffidi P, Ferrera D, Porto A, Bachi A, Rubartelli A, Agresti A and Bianchi ME: Monocytic cells hyperacetylate chromatin protein HMGB1 to redirect it towards secretion. EMBO J 22: 5551-5560, 2003.

16. Youn JH and Shin JS: Nucleocytoplasmic shuttling of HMGB1 is regulated by phosphorylation that redirects it toward secretion. $\mathrm{J}$ Immunol 177: 7889-7897, 2006. 
17. Ito I, Fukuzawa J and Yoshida M: Post-translational methylation of high mobility group box 1 (HMGB1) causes its cytoplasmic localization in neutrophils. J Biol Chem 282: 16336-16344, 2007.

18. Ditsworth D, Zong WX and Thompson CB: Activation of poly(ADP)-ribosepolymerase (PARP-1) induces release of the pro-inflammatory mediator HMGB1 from the nucleus. J Biol Chem 282: 17845-17854, 2007.

19. Ellerman JE, Brown CK, De Vera M,Zeh HJ, Billiar T, Rubartelli A and Lotze M: Masquerader: high mobility group box-1 and cancer. Clin Cancer Res 13: 2836-2848, 2007.

20. Sasahira T, Kirita T, Oue N, Bhawal UK, Yamamoto K, Fujii K, Ohmori H, Luo Y, Yasui W, Bosserhoff AK and Kuniyasu H: High mobility group box-1-inducible melanoma inhibitory activity is associated with nodal metastasis and lymphangiogenesis in ora squamous cell carcinoma. Cancer Sci 99: 1806-1812, 2008.

21. Fages C, Nolo R, Huttunen H, Eskelinen E and Rauvala $H$ : Regulation of cell migration by amphoterin. J Cell Science 113: 611-620, 2000

22. Taguchi A, Blood DC, Del Toro G, Canet A, Lee D.C, Qu W, Tanji N, Lu Y, Lalla E, Fu C, Hofmann MA, Kislinger T, Ingram M,Lu A, Tanaka H,Hori O, Ogawa S, Stern DM and Schmidt AM: Blockade of RAGE-amphoterin signalling suppresses tumour growth and metastases. Nature 405: 354-360, 2000.

23. Kuniyasu H, Chihara $\mathrm{Y}$ and Takahashi T: Co-expression of receptor for advanced glycation end products and the ligand amphoterin associates closely with metastasis of colorectal cancer. Oncol Rep 10: 445-448, 2003.

24. Bierhaus A, Humpert P, Morcos M, Wendt T, Chavakis T, Arnold B, Stern D and Nawroth P: Understanding RAGE, the receptor for advanced glycation end products. J Mol Med 83 876-886, 2005.

25. Sasahira T, Akama Y, Fujii K and Kuniyasu H: Expression of receptor for advanced glycation end products and HMGB1/ amphoterin in colorectal adenomas. Virchows Arch 446: 411-415, 2005.

26. Kostova N, Zlateva S, Ugrinova I and Pasheva E: The expression of HMGB1 protein and its receptor RAGE in human malignant tumors. Mol Cell Biochem 337: 251-258, 2010.
27. Dignam JD: Preparation of extracts from higher eukaryotes. Methods Enzymol 182: 194-203, 1990.

28. Prasad S and Thakur MK: Distribution of high mobility group proteins in different tissues of rats during aging. Biochem Int 20: 687-695, 1990.

29. Muller S, Ronfani L and Bianchi M: Regulated expression and subcellular localization of HMGB1, a chromatin protein with a cytokine function. J Int Med 255: 332-343, 2004.

30. Flohr A, Rogalla P, Meiboom M, Borrmann L, Krohn M, Thode-Halle B and Bullrdiek J: Variation of HMGB1 expression in breast cancer. Anticancer Res 21: 3881-3885, 2001.

31. Bartling B, Hofmann H, Weiglel B, Silber S and Simm A: Down-regulation of the receptor for advanced glycation endproducts (RAGE) supports non-small cell lung carcinoma. Carcinogenesis 26: 293-301, 2005.

32. Merenmies J, Pihlaskari R, Laitinen J, Wartiovaarall J and Rauvala H: 30-kDa heparin-binding protein of brain (amphoterin) involved in neurite outgrowth. J Biol Chem 266: 16722-16729, 1991.

33. Sparvero L, Asafu-Adjei D, Kang R, Tang D, Amin N, Im J, Rutledge R, Lin B, Amoscato A, Zeh H and Lotze M: RAGE (Receptor for Advanced Glycation End products), RAGE ligands and their role in cancer and inflammation. J Transl Med 7: 17-39, 2009.

34. Rouhiainen A, Imai S, Rauvala $\mathrm{H}$ and Parkkinen J: Occurrence of amphoterin (HMG1) as an endogenous protein of human platelets that is exported to the cell surface upon platelet activation. Thromb Haemost 84: 1087-1094, 2000.

35. Passalacqua M, Zicca A, Sparatore B, Patrone M, Melloni E and Pontremoli S: Secretion and binding of HMG1 protein to the external surface of the membrane are required for murine erythroleukemia cell differentiation. FEBS Lett 400: 275-279, 1997. 